\title{
DESIGNER EDUCACIONAL: A IMPORTÂNCIA DESSE PROFISSIONAL
}

Lívia Raposo Bardy ${ }^{1}$, Danielle Aparecida do Nascimento dos Santos ${ }^{2}$

${ }^{1}$ Universidade Estadual Paulista - UNESP, Programa de Pós-Graduação em Educação (PPGE), Presidente Prudente, SP. Universidade do Oeste Paulista - UNOESTE, Curso de Pedagogia a Distância, Presidente Prudente, SP. Fundação Dracenense de Educação e Cultura - UNIFADRA, Licenciaturas, Dracena, SP. ${ }^{2}$ Universidade do Oeste Paulista UNOESTE, Programa de Pós-graduação em Educação e curso de Pedagogia a Distância, Presidente Prudente, SP. Universidade Estadual Paulista, Departamento de Estatística, Presidente Prudente, SP. E-mail: liviarbardy@gmail.com

\section{RESUMO}

Este artigo tem como tema central discutir a importância de um profissional da área da educação que ainda não é muito conhecido, mas que tem grande relevância no cenário atual de inovações e uso de tecnologias educacionais. Esse profissional é o Designer Educacional também conhecido por Designer Instrucional. O objetivo deste estudo, resultado de um trabalho de conclusão de curso de uma pós-graduação, foi o de compreender e evidenciar a importância do profissional Designer Educacional. A metodologia utilizada foi de cunho qualitativo e do tipo bibliográfico. Por meio do estudo foi possível concluir que a presença de um profissional com a formação que tem o Designer Educacional é de fundamental importância e pode trazer inúmeros benefícios para o processo de ensino e aprendizagem nas instituições de ensino, de todos os níveis e modalidades. Assim, torna-se relevante que o âmbito educacional conheça esse profissional.

Palavras-chave: Designer Educacional, Designer Instrucional, Profissional, Educação.

\section{EDUCATIONAL DESIGNER: THE IMPORTANCE OF THIS PROFESSIONAL}

\begin{abstract}
This article is focused on discussing the importance of professional education area that is still not well known, but it has great importance in the current scenario of innovation and use of educational technologies. This professional is the Educational Information also known as Instructional Designer. The purpose of this study, the result of a course conclusion work of a graduate, was to understand and highlight the importance of professional Educational Information. The methodology used was of qualitative nature and bibliographical. Through the study it was concluded that the presence of a professional with training that has the Educational Information is crucial and can bring numerous benefits to the process of teaching and learning in educational institutions of all levels and types. Thus, it is important that the educational scope know this professional.
\end{abstract}

Keywords: Educational Designer, Instructional Designer, Professional Education. 


\section{INTRODUÇÃO}

O cenário educacional como um todo, isto é, mundialmente, tem enfrentado mudanças significativas. Sobretudo, mudanças de cunho metodológico e em relação à postura dos estudantes e também dos docentes. Conforme indica Moran (2002; 2009), nas últimas três décadas a vida cotidiana do ser humano e em consequência, o âmbito educacional também tem sido revolucionado pelo uso das Tecnologias Digitais de Informação e Comunicação (TDIC).

Os diferentes recursos e ferramentas das TDIC têm trazido para o âmbito educacional a possibilidade da melhora significativa da construção do conhecimento aos estudantes de todos os níveis da educação, uma vez que a tecnologia está presente na vida do ser humano, seja criança, jovem, adulto ou idoso.

Por isso diversas pesquisas evidenciam que há sem dúvida uma reconfiguração do paradigma educacional que se dá pela fase intensa de transformações que a sociedade vem passando e entre as mudanças mais significativas estão as de cunho tecnológico que afetam diretamente a dinâmica da sociedade e as formas de ensinar e aprender (SANTOS, 2007; BARDY, 2010).

Essas pesquisas têm comprovado que o uso dessas TDIC podem proporcionar meios que favoreçam a inclusão, social, digital e educacional e que podem possibilitar que o processo de ensino e aprendizagem ocorra de maneira contextualizada e significativa a todos os estudantes e em todos os níveis e modalidades da educação.

No que diz respeito ao uso das TDIC como ferramentas potencializadoras do processo de ensino e aprendizagem, o computador, tem sido uma das ferramentas mais utilizadas. Porém, a abordagem metodológica de uso das TDIC que o docente lança mão deve ser considerada. (BELLONI, 2001). Ou seja, não basta que se use TDIC nos processos de ensino e aprendizagem, mas sim que o uso seja feito com qualidade.

Pode-se resumir que as metodologias que permeiam o uso das TDIC na educação podem ser instrucionistas ou construcionistas. Para Schlünzen (2000), por meio da abordagem construcionista, o estudante pode usar o computador tanto para desenvolver projetos como para resolver problemas reais, o que propicia mudanças positivas nos processos de ensino e aprendizagem em todos os níveis e modalidades da educação, conforme citado anteriormente. Portanto, a abordagem construcionista é a abordagem defendida pelas autoras do presente artigo e que devem estar presentes nos processos formativos que fazem isso das TDIC.

É também importante salientar que quando se fala em processo formativo está se falando de todas as etapas desse processo, isto é, preparação de material didático, construção do conhecimento, mediação e avaliação.

Por isso, essas etapas devem ser exercidas com qualidade, devem levar o estudante, sobretudo por meio da mediação, se sentir instigado a resolver problemas, dando maior significado à construção de sua aprendizagem. A avaliação da aprendizagem, por sua vez, deve ocorrer de maneira sistêmica, ou seja, de maneira que se compreendam os aspectos de gestão pedagógica, mediação, comunicação, e relacionadas à construção e oferta de material didático (NEDER, 1996; VALENTE, 2003).

Independente de qual nomenclatura é utilizada, a adoção das autoras é pela nomenclatura Designer Educacional, o entendimento sobre o que faz o profissional é o mesmo, ou seja, é um profissional que exerce atividades de planejamento, execução e acompanhamento de processos educacionais. Por isso, a seguir estão apresentados o conceito do que venha a ser Designer Instrucional ou Instrucional.

De acordo com Silva, Diana e Spanhol (s/d, p.02), o designer é "profissional com ação múltipla nos projetos de educação a distância, pois além de participar de diferentes fases do projeto auxilia e orienta a sua direção e de uma grande equipe, muitas vezes". 
O Designer Instrucional ou Educacional é um profissional da educação que se compromete com a melhoria da aprendizagem, por isso, oferece atenção às necessidades que os estudantes podem apresentar e a busca pela aprendizagem ativa, bem como pelo dinamismo que pode haver na aprendizagem.

Para Filatro (2004) o Designer exerce uma ação institucional e sistemática de ensino, muito importante que envolve o planejamento, o desenvolvimento e a utilização de métodos, técnicas, atividades, materiais e produtos educacionais em situações didáticas, que têm a finalidade de promover a aprendizagem humana.

Para França (2007), o Designer é um profissional que conhece teorias, tem prática pedagógica, faz uso das mídias e tem conhecimento das novas linguagens tecnológicas, por isso, pode estabelecer relações significativas com a concepção dos processos de formação em que atua.

Nesse ínterim, uma das principais funções do Designer é a de impregnar nos princípios didáticos a qualidade dos materiais, atividades e interação com o estudante. Pontos de fundamental importância e qualquer processo de ensino. O Designer é também um profissional que se dedica a deixar os processos de ensino mais dialógicos, de oportunizar maior proximidade entre o estudante e o docente, por exemplo. Fazendo assim com que haja mais dinamismo no processo educacional.

\section{CONHECENDO AS ÁREAS DE ATUAÇÃO DO DESIGNER EDUCACIONAL}

Embora haja o entendimento de que o Designer Educacional seja um profissional que atua de maneira específica na EaD pelo fato de que foi nessa modalidade de ensino que esse profissional, essa função nasceu.

Todavia, por meio dos estudos realizados e da prática vivenciada, foi possível perceber que dentro do âmbito educacional, o Designer Educacional, poderá atuar nas diferentes modalidades presencial, a distância, semipresencial e ainda nos diferentes níveis do ensino.

Ou seja, todas as instituições de ensino, educação básica, ensino superior, ensino profissional e técnico podem e devem ter um profissional com a formação de um Designer Educacional, haja vista que trata-se de um profissional que em sua essência busca aprimorar os processos de ensino e aprendizagem. É um profissional que está então a serviço da aprendizagem, portanto da educação, e esta é algo que existe independente da modalidade ou nível.

Assim, o objetivo deste estudo foi de compreender, evidenciar e até mesmo divulgar a importância do profissional Designer Educacional no âmbito educacional. A seguir está apresenta, de maneira breve, a metodologia utilizada no presente estudo.

\section{METODOLOGIA}

A metodologia utilizada no estudo foi qualitativa do tipo bibliográfica. Para Neves (1996), a pesquisa qualitativa costuma ser direcionada sem o uso de instrumento estatístico, pois busca obter dados descritivos em contato direto e interativo com a situação do objeto de estudo.

Assim, por meio do estudo bibliográfico realizado foi possível atingir o objetivo proposto para o presente trabalho que foi o de compreender e evidenciar a importância do profissional Designer Educacional no âmbito educacional. Para isso, recorrer à literatura é fundamental.

\section{RESULTADOS}

Os resultados alcançados revelam que existem poucos estudos sobre a temática, o que dificulta que a disseminação da importância desse profissional seja feita.

Outro resultado alcançado foi o entendimento pleno de que o Designer Educacional não deve ser visto somente como um profissional da $\mathrm{EaD}$, mas sim da educação, já que sua função é a 
de melhorar os processos de ensino e aprendizagem, tornando-o mais dinâmico, ativo, contextualizado e significativo.

\section{DISCUSSÃO}

Por meio dos estudos realizados durante o trabalho de conclusão de curso da pósgraduação da Unoeste, além da experiência pessoal e profissional vivenciada pelas autoras, é possível afirmar que âmbito educacional, por meio de suas diversas instituições de ensino, deve conhecer melhor a função do Designer Educacional pelos benefícios ao processo de ensino e aprendizagem que pode proporcionar.

Por isso, considera-se que seja relevante que as instituições de ensino, de todos os níveis e modalidades de ensino, possam aos poucos, ter em seu quadro de funcionários um Designer Educacional, uma vez que esse profissional tem subsídios importantes para o processo educacional mediado pelos diferentes recursos e ferramentas das TDIC, que é uma realidade do mundo contemporâneo.

Além disso, a presença de um profissional como o Designer Educacional nas instituições de ensino pode fazer com que o ensino seja mais o qualitativo possível e que tenha maiores possibilidades de oportunizar aos estudantes e, futuros profissionais do país, aprendizagens significativas compatíveis com os avanços da ciência e da tecnologia.

\section{CONCLUSÃO}

As instituições de Ensino Superior têm demonstrado preocupação com a melhora da qualidade do ensino e com a formação dos profissionais que irão para o mundo do trabalho, por isso, o Designer Educacional tem grande importância no apoio aos docentes que desejam desenvolver disciplinas ou cursos no formato blended ou a distância, bem como para dinamizar as aulas presenciais. Assim, as instituições de Ensino Superior precisam ter em seu quadro de profissionais, um Designer Educacional para auxiliar os docentes com a inovação dos processos educacionais.

Para isso, faz-se necessário que a comunidade científica e educacional conheça esse profissional, suas atribuições e então, tê-lo como integrante das diversas instituições de ensino de nosso país, que almeja a melhora do ensino e da aprendizagem.

\section{REFERÊNCIAS}

BARDY, L.R. Objetos de Aprendizagem em Contextos Inclusivos: Subsídios para a Formação de Professores. Dissertação (Mestrado em Educação Especial). Programa de Pós Graduação em Educação Especial, Universidade Federal de São Carlos. São Carlos, 2010.

BELLONI, M. L. O que é mídia-educação? Campinas: Autores Associados, 2001.

FILATRO, A. Design Instrucional contextualizado: educação e tecnologia. São Paulo: Senac. 2004.

FILATRO, A. Design Instrucional na Prática. Pearson. 2008.

FRANÇA, G. O Design instrucional na Educação a Distância. São Paulo: Esfera, 2007.

MORAN, J. M. Como utilizar a internet na educação. (artigo publicado na Revista Ciência da Informação, Vol. 26, n.2, maio-agosto 1997, pág. 146-153). Disponível em: http://www.eca.usp.br/prof/moran/i. Acesso em: 25 set. 2009. 
NEDER, Maria Lúcia C. Avaliação na Educação a Distância: significações para definição de percursos. In: PRETI, O. (Org.). Educação a Distância: inícios e indícios de um percurso. Cuiabá: EdUFMT, 1996.

SANTOS, D. A. N. A formação de professores de uma escola da rede pública estadual em serviço para o trabalho com projetos usando as Tecnologias de Informação em Comunicação. Presidente Prudente, 2007. Dissertação (Mestrado em Educação) FCT/Unesp, 2007.

SCHLÜNZEN, E. T. M. Mudanças nas Práticas Pedagógicas do Professor: criando um ambiente construcionista contextualizado e significativo para crianças com necessidades especiais físicas. São Paulo, 2000. Tese (Doutorado em Educação: Currículo). Pontifícia Universidade Católica de São Paulo (PUC_SP).

SILVA, A.R.L.; DIANA, J.B.; SPANHOL, F,J. Designer Instrucional: da formação múltipla a ação interdisciplinar. Simpósio Internacional sobre Interdisciplinaridade no Ensino, Pesquisa e Extensão - Região Sul. Universidade Federal de Santa Catarina. Santa Catarina.

VALENTE, J.A. Educação a distância no ensino superior: soluções e flexibilizações. Interface Comunic, Saúde, Educ, v7, n12, p.139-48, fev 2003. Disponível em: http://www.scielo.br/pdf/icse/v7n12/v7n12a09.pdf Acesso em: 06. Jun.2015. 